\section{Urologia \\ Internationalis}

\title{
Vitamin D Receptor Genetic Polymorphisms and the Risk of Urolithiasis: A Meta-Analysis
} Affiliated Hospital, School of Medicine, Zhejiang University, Hangzhou, PR China

\section{Yiwei Lin Qiqi Mao Xiangyi Zheng Hong Chen Kai Yang Liping Xie}

Department of Urology, The First

\section{Introduction}

Urolithiasis is associated with many complicated factors. It can be triggered by environmental influences, metabolic defects and genetic factors [1,2]. The tendency of stone formation is largely attributed to excessive calcium absorption, since calcium is the principal crystalline constituent in up to $80 \%$ of kidney stones [2]. VDR is a 50- to $60-\mathrm{kDa}$ cellular polypeptide that plays a central role in mineral metabolism, including calcium homeostasis and tubular citrate handling. It could facilitate the active form of vitamin $\mathrm{D}$ with calcium absorption and citrate excretion $[3,4]$. Any alteration in the vitamin D receptor (VDR) may change the mineral metabolism, thus consequently be associated with altered urolithiasis risk.

A growing amount of epidemiologic evidence has suggested that allelic variations in the VDR gene may be involved in the etiology of urinary stone disease. The four most common single nucleotide polymorphisms (SNPs), i.e., ApaI, BsmI, TaqI and FokI, which were hypothesized to influence the expression and/or function of the VDR protein [4-6], had earned the focus in a search for candidate genetic markers associated with urolithiasis. ApaI, BsmI and TaqI located in the 3' UTR region of the VDR gene were supposed to affect the mRNA stability or change vitamin D activity via translation regulation [4]. FokI located in the exon 2. It was functionally significant

Dr. Liping Xie

Department of Urology, The First Affiliated Hospital, School of Medicine

Zhejiang University, Qingchun Road 79

Hangzhou 310003, Zhejiang (PR China)

Tel. +86 5718723 6735, E-Mail xielp@zjuem.zju.edu.cn 
and associated with transactivation of the vitamin D signal [5]. Numerous studies have been dedicated to interpreting the possible association between the mentioned polymorphisms and urolithiasis susceptibility. However, the results were inconclusive. For instance, Jackman et al. [7] observed that the TT genotype in TaqI polymorphism was associated with more aggressive stone disease, both within families and with respect to recurrence. Mossetti et al. [8] found associations between the BsmI and TaqI polymorphisms and idiopathic hypocitraturia in recurrent calcium oxalate stone disease. The most recent study by Mittal et al. [9] indicated that both Tt genotype of TaqI polymorphism and Ff of FokI polymorphism demonstrated a significantly higher risk for stone formation $(\mathrm{OR}=1.830$ and 3.559 , respectively). However, the analysis by Chen et al. [10] revealed that the BsmI polymorphism of the VDR gene was not a suitable genetic marker for urinary stone disease. Seo et al. [11] and Gunes et al. [12] reported that VDR polymorphisms did not confer a significant risk for urinary stones.

The controversial results across many of these studies could possibly be related to the small sample size from an individual study, ethnic difference or the biological genetic model applied for the analysis. Therefore, it was necessary to quantify the potential between-study heterogeneity and summarize results from all eligible studies with rigorous methods. In the present study, a metaanalysis with the most updated data was performed to revisit the association between VDR variants (i.e., ApaI, BsmI, FokI and TaqI) and urolithiasis risk.

\section{Materials and Methods}

\section{Literature Search}

The studies considered in this meta-analysis were case-control studies exploring the association between VDR polymorphic sites ApaI, BsmI, TaqI and FokI, and urolithiasis risk. An initial literature search was conducted within the PubMed database up to September 2010, using MeSH terms, 'urolithiasis', 'vitamin D', and 'receptors, calcitriol'. Additional studies were identified from references cited in retrieved articles. Eligible studies had to fulfill all the following inclusion criteria: (a) case-control study evaluating the association between VDR polymorphisms and urolithiasis risk, (b) the polymorphic sites should include at least one of the mentioned sites, i.e. BsmI, ApaI, FokI or TaqI, and (c) distribution of each genotype in patients and controls should be determined. In studies with overlapping patients or controls, only the latest or the most complete was included. Any study with inconsistent or erroneous data was excluded. Meeting abstracts with insufficient data or unpublished reports were not considered.

\section{Data Extraction}

Two investigators independently extracted data from all potentially relevant studies. Conflicting evaluations were resolved by discussion. When needed, the third-party resolution was sought. Data extracted from these articles included the name of the first author, year of publication, number of cases and controls, region/ethnicity, and genotype frequencies for cases and controls.

\section{Statistical Analysis}

OR and 95\% CI were estimated for the strength of the association between ApaI, BsmI, TaqI and FokI polymorphisms and urolithiasis risk respectively. The pooled ORs were performed for allelic comparison, a dominant model, and a recessive model in each of the above polymorphic sites $[13,14]$. Between-study heterogeneity across the eligible comparisons was quantitatively assessed using the $\chi^{2}$-based $Q$ statistical test and $\mathrm{I}^{2}$ test $[15,16]$. Heterogeneity was considered significant when $\mathrm{p}<0.05$. The data from single comparison was combined using fixed-effect model with the Mantel-Haenszel method [17] when no heterogeneity presented. Otherwise, the random-effect model with the DerSimonian-Laird method [18] was used for pooling. The potential publication bias was estimated statistically by Egger's test [19]. Considering the capacity of bias detection, the publication bias was only computed for the analysis including more than 8 studies [19]. $\mathrm{p}<0.05$ was considered indicative of significant publication bias. To test for population stratification, the distributions of genotypes in the controls were tested for Hardy-Weinberg equilibrium (HWE). Regarding the impact of HWE, studies with the controls not in HWE were subjected to a sensitivity analysis [14]. In addition, subgroups in terms of ethnics or stone composition were stratified. Those with more than 2 studies were summarized. All statistical analyses were performed with STATA version 10.1 (StataCorp, College Station, Tex., USA). All p values were twosided.

\section{Results}

\section{Eligible Studies}

A total of 22 eligible articles were retrieved [7-12, 2035]. Three studies [8, 27, 32] with overlapping data were discussed in detail for inclusion. Those with a control group in HWE were considered higher priority [27, 32]. The study with mistyped data [30] and the studies without a control group $[22,24,35]$ were excluded. Finally, 17 studies (table 1) were included in our meta-analysis. There were 7 exploring the association between ApaI polymorphism and urolithiasis, 6 for BsmI, 9 for FokI, and 9 for TaqI. Since most studies did not provide details on ethnic features, ethnic subgroup analysis should be done according to the regional characteristics, which would instead be stratified as Asia, America and Europe. Subgroup analysis on calcium stone should also be performed with studies providing specified stone composition data according to either calculous analysis or imaging. 
Table 1. List and characteristics of studies included in the meta-analysis

\begin{tabular}{llllrrl}
\hline Year & $\begin{array}{l}\text { Reference } \\
\text { (first author) }\end{array}$ & Region & $\begin{array}{l}\text { Stone } \\
\text { composition }^{1}\end{array}$ & Cases & Controls & Polymorphic sites (HWE status $\left.{ }^{2}\right)$ \\
\hline 1999 & Ruggiero [20] & Europe & NS & 27 & 150 & BsmI (N) \\
1999 & Jackman [7] & America & Calcium & 17 & 37 & TaqI (N) \\
2001 & Chen [10] & Asia & Calcium & 124 & 90 & BsmI (N) \\
2001 & Chen [21] & Asia & Calcium & 146 & 90 & FokI (Y) \\
2002 & Nishijima [23] & Asia & Calcium & 83 & 83 & ApaI (Y), TaqI (Y) \\
2003 & Ozkaya [25] & Europe & Calcium & 64 & 90 & ApaI (N), BsmI (Y), TaqI (Y) \\
2003 & Wang [34] & Asia & Calcium & 150 & 80 & ApaI (Y), FokI (Y), TaqI (Y) \\
2004 & Mossetti [32] & Europe & Calcium & 110 & 127 & TaqI (Y) \\
2004 & Rendina [27] & Europe & Calcium & 159 & 124 & ApaI (Y), BsmI (Y), FokI (Y) \\
2004 & Relan [26] & Asia & Calcium & 150 & 100 & BsmI (N), FokI (N) \\
2005 & Bid [28] & Asia & Calcium & 50 & 60 & FokI (N) \\
2005 & Bid [33] & Asia & Calcium & 138 & 166 & FokI (N) \\
2006 & Gunes [12] & Europe & Calcium & 110 & 150 & ApaI (Y), BsmI (Y), TaqI (Y) \\
2007 & Liu [29] & Asia & Calcium & 235 & 231 & FokI (Y) \\
2007 & Seyhan [31] & Europe & Calcium & 80 & 40 & TaqI (N) \\
2009 & Seo [11] & Asia & NS & 278 & 535 & ApaI (N), FokI (N), TaqI (N) \\
2010 & Mittal [9] & Asia & NS & 125 & 150 & ApaI (Y), FokI (N), TaqI (Y) \\
\hline
\end{tabular}

\footnotetext{
1 'NS' indicates stone composition was not specified, while 'Calcium' indicates calcium stone.

2 ' $\mathrm{N}$ ' indicates the genotype distribution of the corresponding control group deviated from HWE, 'Y' indicates the consistence with HWE.
}

\section{ApaI Polymorphism}

Seven studies associating ApaI and urolithiasis risk were identified from the literature search. Between-study heterogeneity was detected only in the dominant genetic model for the Europe subgroup $\left(\mathrm{P}_{\text {heterogeneity }}=0.014\right.$, $\left.\mathrm{I}^{2}(\%)=76.7\right)$ and calcium stone subgroup $\left(\mathrm{P}_{\text {heterogeneity }}=\right.$ $\left.0.027, \mathrm{I}^{2}(\%)=63.5\right)$, so the DerSimonian-Laird method for the random-effect model was applied in these subgroup analyses. The pooled OR from overall studies indicated no significant association between ApaI polymorphisms and urolithiasis risk in allelic comparison $(\mathrm{OR}=0.94$, 95\% CI $0.83,1.07)$, dominant model ( $\mathrm{OR}=0.91,95 \% \mathrm{CI}$ $0.75,1.10)$ or recessive model $(\mathrm{OR}=0.96,95 \%$ CI 0.76 , 1.21). Sensitivity analysis after excluding the studies with controls deviating from HWE did not alter the pattern of results (table 2). Also, no specific relationship between ApaI polymorphism and calcium stone was found in any of the above comparisons (table 2). Furthermore, a regional specific subgroup analysis could not detect any significant association (table 2).

\section{BsmI Polymorphism}

A similar result to ApaI polymorphism was obtained after summarizing 6 studies exploring the association be- tween BsmI polymorphism and urolithiasis risk. No significant association in pooled OR for overall studies was detected in allelic comparison $(\mathrm{OR}=1.12,95 \%$ CI 0.94 , 1.32), dominant model ( $\mathrm{OR}=1.23,95 \%$ CI $0.92,1.63$ ) or recessive model $(\mathrm{OR}=1.09,95 \% \mathrm{CI} 0.83,1.42)$. The sensitivity analysis results suggested that there was no significant influence of the individual data deviating from HWE set to the overall pooled OR. In the subgroup analyses by region and calcium stone, no significant result was observed either (table 3).

\section{FokI Polymorphism}

For the association between FokI polymorphism and urolithiasis risk, 9 studies were retrieved. Between-study heterogeneity was considered according to $\chi^{2}$-based $\mathrm{Q}$ statistical test and $\mathrm{I}^{2}$ test (table 4). The random-effect model was therefore applied. The summarization of overall studies with allelic comparison $(\mathrm{OR}=1.26,95 \% \mathrm{CI}$ $\left.1.00,1.59, \mathrm{P}_{\text {heterogeneity }}<0.001, \mathrm{I}^{2}(\%)=77.6\right)$ indicated a marginal increased in urolithiasis risk with $\mathrm{f}$ allele. However, the overall results from the dominant model $\left(\mathrm{OR}=1.55,95 \%\right.$ CI 0.99, 2.41, $\mathrm{P}_{\text {heterogeneity }}<0.001, \mathrm{I}^{2}(\%)=$ 85.4) and recessive model $(\mathrm{OR}=1.10,95 \%$ CI $0.79,1.52$, $\left.\mathrm{P}_{\text {heterogeneity }}=0.039, \mathrm{I}^{2}(\%)=50.7\right)$ showed no significant 
Table 2. Results of allelic and genotypic association analysis for the ApaI polymorphism

\begin{tabular}{lclc}
\hline Category & OR $(95 \% \mathrm{CI})$ & $\mathrm{P}_{\text {heterogeneity }}$ & $\mathrm{I}^{2}, \%$ \\
\hline Allelic comparison $(a$ vs. A) & & \\
All & $0.94(0.83,1.07)$ & 0.294 & 17.8 \\
Asia & $0.94(0.80,1.10)$ & 0.431 & 0 \\
Europe & $0.95(0.77,1.18)$ & 0.104 & 55.9 \\
Calcium stone & $0.88(0.74,1.05)$ & 0.202 & 32.9 \\
All in HWE & $0.95(0.80,1.11)$ & 0.524 & 0 \\
\hline Dominant model $($ Aa + aa $v$ s. AA) & & \\
All & $0.91(0.75,1.10)$ & 0.058 & 50.8 \\
Asia & $0.89(0.71,1.12)$ & 0.322 & 14 \\
Europe & $0.75(0.34,1.66)$ & 0.014 & 76.7 \\
Calcium stone & $0.71(0.42,1.19)$ & 0.027 & 63.5 \\
All in HWE & $0.99(0.76,1.27)$ & 0.338 & 11.8 \\
\hline Recessive model (aa vs. AA $A a)$ & & \\
All & $0.96(0.76,1.21)$ & 0.344 & 11.1 \\
Asia & $0.98(0.74,1.29)$ & 0.145 & 44.4 \\
Europe & $0.93(0.63,1.38)$ & 0.52 & 0 \\
Calcium stone & $0.88(0.66,1.16)$ & 0.789 & 0 \\
All in HWE & $0.86(0.64,1.14)$ & 0.689 & 0 \\
\hline
\end{tabular}

Table 3. Results of allelic and genotypic association analysis for the BsmI polymorphism

\begin{tabular}{lccc}
\hline Category & OR $(95 \% \mathrm{CI})$ & $\mathrm{P}_{\text {heterogeneity }}$ & $\mathrm{I}^{2}, \%$ \\
\hline Allelic comparison $(b$ vs. B) & & \\
All & $1.12(0.94,1.32)$ & 0.283 & 19.9 \\
Asia & $1.23(0.89,1.70)$ & 0.272 & 17.1 \\
Europe & $1.07(0.88,1.31)$ & 0.208 & 34 \\
Calcium stone & $1.08(0.90,1.29)$ & 0.301 & 17.8 \\
All in HWE & $1.02(0.82,1.27)$ & 0.249 & 28 \\
\hline Dominant model $(B b+b b v s . B B)$ & & \\
All & $1.23(0.92,1.63)$ & 0.398 & 2.8 \\
Asia & $1.44(0.93,2.24)$ & 0.116 & 59.6 \\
Europe & $1.09(0.76,1.58)$ & 0.636 & 0 \\
Calcium stone & $1.26(0.94,1.68)$ & 0.335 & 12.3 \\
All in HWE & $1.13(0.77,1.67)$ & 0.502 & 0 \\
\hline Recessive model $(b b v s . ~ B B$ & & \\
All & $B b)$ & & \\
Asia & $1.09(0.83,1.42)$ & 0.054 & 54 \\
Europe & $1.03(0.60,1.76)$ & 0.934 & 0 \\
Calcium stone & $1.28(0.70,2.35)$ & 0.013 & 72.1 \\
All in HWE & $0.98(0.74,1.29)$ & 0.516 & 0 \\
& $0.96(0.69,1.33)$ & 0.201 & 37.6 \\
\hline
\end{tabular}

Table 4. Results of allelic and genotypic association analysis for the FokI polymorphism

\begin{tabular}{|c|c|c|c|}
\hline Category & OR (95\% CI) & $\mathrm{P}_{\text {heterogeneity }}$ & $\mathrm{I}^{2}, \%$ \\
\hline \multicolumn{4}{|c|}{ Allelic comparison ( $f$ vs. $F$ ) } \\
\hline All & $1.26(1.00,1.59)$ & $<0.001$ & 77.6 \\
\hline Asia & $1.30(1.00,1.68)$ & $<0.001$ & 79.8 \\
\hline Europe & - & - & - \\
\hline Calcium stone & $1.24(0.92,1.69)$ & $<0.001$ & 80.3 \\
\hline All in HWE & $1.07(0.76,1.50)$ & 0.002 & 76.5 \\
\hline \multicolumn{4}{|c|}{ Dominant model $(F f+f f v s . F F)$} \\
\hline All & $1.55(0.99,2.41)$ & $<0.001$ & 85.4 \\
\hline Asia & $1.65(1.00,2.72)$ & $<0.001$ & 86.7 \\
\hline Europe & - & - & - \\
\hline Calcium stone & $1.50(0.88,2.55)$ & $<0.001$ & 84.5 \\
\hline All in HWE & $1.08(0.67,1.75)$ & 0.006 & 72.1 \\
\hline \multicolumn{4}{|c|}{ Recessive model (ff vs. FF $+F f)$} \\
\hline All & $1.10(0.79,1.52)$ & 0.039 & 50.7 \\
\hline Asia & $1.09(0.75,1.58)$ & 0.024 & 50.7 \\
\hline Europe & - & - & - \\
\hline Calcium stone & $1.08(0.70,1.64)$ & 0.025 & 58.5 \\
\hline All in HWE & $1.04(0.61,1.76)$ & 0.018 & 66.4 \\
\hline
\end{tabular}

Table 5. Results of allelic and genotypic association analysis for the TaqI polymorphism

\begin{tabular}{|c|c|c|c|}
\hline Category & OR $(95 \% \mathrm{CI})$ & $\mathrm{P}_{\text {heterogeneity }}$ & $\mathrm{I}^{2}, \%$ \\
\hline \multicolumn{4}{|c|}{ Allelic comparison $(t$ vs. $T)$} \\
\hline All & $1.15(1.00,1.34)$ & 0.869 & 0 \\
\hline Asia & $1.23(0.99,1.52)$ & 0.567 & 0 \\
\hline Europe & $1.09(0.88,1.35)$ & 0.754 & 0 \\
\hline America & - & - & - \\
\hline Calcium stone & $1.16(0.98,1.38)$ & 0.718 & 0 \\
\hline All in HWE & $1.15(0.98,1.36)$ & 0.674 & 0 \\
\hline \multicolumn{4}{|c|}{ Dominant model $(T t+t t v s . T T)$} \\
\hline All & $1.28(1.05,1.56)$ & 0.811 & 0 \\
\hline Asia & $1.40(1.07,1.82)$ & 0.621 & 0 \\
\hline Europe & $1.11(0.81,1.52)$ & 0.7 & 0 \\
\hline America & - & - & - \\
\hline Calcium stone & $1.26(0.98,1.61)$ & 0.758 & 0 \\
\hline All in HWE & $1.34(1.07,1.69)$ & 0.656 & 0 \\
\hline \multicolumn{4}{|c|}{ Recessive model $(t t v s . T T+T t)$} \\
\hline All & $1.04(0.77,1.40)$ & 0.254 & 21.3 \\
\hline Asia & $0.95(0.58,1.56)$ & 0.35 & 8.5 \\
\hline Europe & $1.15(0.78,1.71)$ & 0.101 & 51.9 \\
\hline America & - & - & - \\
\hline Calcium stone & $1.15(0.83,1.60)$ & 0.192 & 31 \\
\hline All in HWE & $0.96(0.69,1.33)$ & 0.464 & 0 \\
\hline
\end{tabular}


association between FokI polymorphism and urolithiasis risk. Sensitivity analysis by excluding the studies with controls deviating from HWE suggested no evidence of alteration in the association, with an insignificant association for the summarization of studies in HWE (table 4). In the further regional specific stratified analysis, the $\mathrm{Ff}+\mathrm{ff}$ genotype in the dominant genetic model (OR = $1.65,95 \%$ CI 1.00, 2.72, $\left.\mathrm{P}_{\text {heterogeneity }}<0.001, \mathrm{I}^{2}(\%)=86.7\right)$ and f allelic $\left(\mathrm{OR}=1.30,95 \% \mathrm{CI} 1.00,1.68, \mathrm{P}_{\text {heterogeneity }}<\right.$ $\left.0.001, \mathrm{I}^{2}(\%)=79.8\right)$ presented with a marginally positive relationship to susceptibility for urolithiasis in the Asia subgroup (table 4). Publication bias of the overall analysis in three comparison models was assessed by Egger's test separately. No publication bias was detected according to Egger's test (allelic comparison: $\mathrm{p}=0.297$; dominant model: $\mathrm{p}=0.183$; recessive model: $\mathrm{p}=0.296$ ).

\section{TaqI Polymorphism}

When all of the 9 studies were pooled, no significant between-study heterogeneity was detected (table 5). Marginal positive association was found between the TaqI polymorphism and urolithiasis risk in overall allelic comparison $(\mathrm{OR}=1.15,95 \% \mathrm{CI} 1.00,1.34)$, while the pooled analyses in the dominant model and recessive model were insignificant $(\mathrm{OR}=1.28,95 \% \mathrm{CI} 1.05,1.56$; $\mathrm{OR}=1.04,95 \%$ CI $0.77,1.40$, respectively). However, sensitivity analysis after excluding all the studies with controls deviating from HWE indicated an increased urolithiasis risk associated with $\mathrm{tt}+\mathrm{Tt}$ genotype in the dominant model $(\mathrm{OR}=1.34,95 \%$ CI 1.07, 1.69). Stratified analysis according to the regional characteristics suggested a similar significant association in the dominant genetic model in the Asia subgroup (OR $=1.40,95 \%$ CI 1.07, 1.82) while the other subgroups yielded insignificant results (table 5). Further calcium stone-specific association also yielded insignificant results (table 5). In Egger's test for publication bias of the overall analysis, no bias was detected (allelic comparison: $\mathrm{p}=0.481$; dominant model: $\mathrm{p}=0.667$; recessive model: $\mathrm{p}=0.578$ ).

\section{Discussion}

It is quite reasonable to identify a genetic marker with a significant relationship to susceptibility for urinary stone disease. A well-established genetic marker surely would have a profound influence in screening and prevention of urolithiasis [36, 37], even though the diagnosis of urolithiasis mostly depends on imaging. A lot of genetic epidemiological studies have been conducted to ex- plore the relationship between SNPs and urolithiasis. A wide range of genetic markers have been examined, including polymorphisms of genes coding for the VDR [7$12,20-35]$, interleukin $[38,39]$, fibronectin [40] and urokinase [41-43]. As one of the most important genes related with calcium metabolism, VDR gene has earned special concern. Biological evidence has clearly illustrated the role of VDR in calcium metabolism [44]. In the genetic hypercalciuric rat model, Li et al. [45] found that increase in the number of intestinal VDR was associated with increased calcium absorption. The epidemiological data from Zhu et al. [46] indicated a genetic association between BsmI, FokI and TaqI VDR polymorphisms and idiopathic hypocitraturia. The study by Ferreira et al. [35] suggested that bb homozygous for BsmI polymorphisms in VDR was overrepresented in hypercalciuric stone formers. However, genetic epidemiological studies investigating urolithiasis markers yielded conflicting results, which indicated that identifying a genetic marker for urolithiasis remains a big challenge.

Herein, we quantitatively summarized all these epidemiological studies to provide an evidence-based clue for the genetic markers located on VDR gene for urolithiasis. To the best of our knowledge, our current meta-analysis was the first quantitative summarization examining four well-characterized SNPs of the VDR gene for their relevance to urolithiasis. This meta-analysis examined the ApaI, BsmI, FokI and TaqI polymorphisms of the VDR gene and their relationship to urolithiasis. The associations for the allele contrast, the dominant model and recessive model were examined.

In our analysis, both ApaI and BsmI were not associated with urolithiasis risk. The sensitivity analysis for the studies not in HWE did not alter the insignificant results. Further quantitative assay stratified by regional information and stone type also yielded null results. These results could be reinforced by previous studies [47] which proposed that absorptive hypercalciuria (a stone-forming condition) was not attributable to variation of the VDR genotypes. However, it should still be interpreted with caution considering the limited number of primary studies. The null results could possibly be due to an inadequate number of primary studies to detect the strength of the postulated associations. Also, there existed a possibility that the complex etiology of urolithiasis which included diet and living habits would probably mask the positive association while a single study in our analysis could not provide sufficient information. While FokI was analyzed, our result demonstrated a marginal effect of FokI polymorphism on the risk of urolithiasis. However, se- 
vere between-study heterogeneity was found. One of the most critical factors contributing to such heterogeneity might be the diverse genotype distributions of FokI in studies. Also, the uneven selection criteria for the case and control in different studies would generate heterogeneity. Even though derived from a set of heterogeneous studies, the results from the Asia subgroup revealed an increased urolithiasis risk with $\mathrm{ff}+\mathrm{Ff}$ genotype in the dominant model or $\mathrm{f}$ allele in allelic comparison. The positive association was also found in overall allelic comparison. Several arguments contradicted these findings. Jurutka et al. [48] found that $\mathrm{F}$ allele interacted more efficiently with basal transcription factor IIB and possessed higher transcriptional activity. Similarly, in the molecular research done by Whitfield et al. [6], the 424-aminoacid short VDR variant (corresponding to the ' $F$ ' allele) represented a more transcriptionally potent VDR protein. An epidemiological study by Liu et al. [29] also suggested $\mathrm{F}$ allele would carry a greater hazard regarding stone episodes and the age of the first stone onset. The confusing results surely indicated a further functional study on FokI polymorphism. In the quantitative assay for TaqI polymorphism, a mild increase in urolithiasis risk was found in the $\mathrm{tt}+\mathrm{Tt}$ genotype compared with TT. The result remained stable in the sensitivity analysis and the Asia subgroup. A marginal increase in urolithiasis risk with $t$ allele in allelic comparison was also detected. However, the Europe subgroup analysis did not support the effect of $t$ allele in urolithiasis risk, which indicated a possible difference in genetic background.

Despite the findings from our current analysis, we still have to acknowledge several limitations. Meta-analysis cannot correct all the biases of individual studies. Considering the multifactorial etiology in urolithiasis, a more precise assay should be based on adjusted estimates according to covariates such as age, lifestyle and environmental factors. We have made many efforts including testing the publication bias, conducting sensitivity and subgroup analysis to acquire a more accurate estimate. However, regional information cannot completely represent an ethnic group's genetic background and strong linkage disequilibrium exists among ApaI, BsmI and TaqI $[4,49]$. Furthermore, this linkage disequilibrium varied in different ethnic groups [49]. These would probably bias our results. Many more well-designed case-control studies with more detailed information are needed to investigate the potential multigenetic predisposition of the disease and to validate our findings.

In summary, evidence from our meta-analysis supports the fact that some VDR gene polymorphisms are associated with an increase in the probability of urolithiasis with certain populations under an indicated genetic model. Considering the predictive value, it warrants further investigation to better clarify these SNP-urolithiasis associations and to reinforce our findings.

\section{References}

1 Goodman HO, Holmes RP, Assimos DG: Genetic factors in calcium oxalate stone disease. J Urol 1995;153:301-307.

-2 Worcester EM, Coe FL: Clinical practice. Calcium kidney stones. N Engl J Med 2010; 363:954-963.

- 3 Simpson DP: Citrate excretion: a window on renal metabolism. Am J Physiol 1983; 244:F223-F234.

-4 Morrison NA, Qi JC, Tokita A, Kelly PJ, Crofts L, Nguyen TV, Sambrook PN, Eisman JA: Prediction of bone density from vitamin D receptor alleles. Nature 1994;367:284-287.

5 Gross C, Krishnan AV, Malloy PJ, Eccleshall TR, Zhao XY, Feldman D: The vitamin D receptor gene start codon polymorphism: a functional analysis of FokI variants. J Bone Miner Res 1998;13:1691-1699.
-6 Whitfield GK, Remus LS, Jurutka PW, Zitzer H, Oza AK, Dang HT, Haussler CA, Galligan MA, Thatcher ML, Encinas Dominguez C, Haussler MR: Functionally relevant polymorphisms in the human nuclear vitamin D receptor gene. Mol Cell Endocrinol 2001;177: 145-159.

7 Jackman SV, Kibel AS, Ovuworie CA, Moore RG, Kavoussi LR, Jarrett TW: Familial calcium stone disease: TaqI polymorphism and the vitamin D receptor. J Endourol 1999;13: 313-316.

8 Mossetti G, Vuotto P, Rendina D, Numis FG, Viceconti R, Giordano F, Cioffi M, Scopacasa F, Nunziata V: Association between vitamin D receptor gene polymorphisms and tubular citrate handling in calcium nephrolithiasis. J Intern Med 2003;253:194-200.
-9 Mittal RD, Mishra DK, Srivastava P, Manchanda P, Bid HK, Kapoor R: Polymorphisms in the vitamin $D$ receptor and the androgen receptor gene associated with the risk of urolithiasis. Indian J Clin Biochem 2010; 25:7.

10 Chen WC, Chen HY, Hsu CD, Wu JY, Tsai FJ: No association of vitamin D receptor gene BSMI polymorphisms with calcium oxalate stone formation. Mol Urol 2001;5:7-10.

-11 Seo IY, Kang IH, Chae SC, Park SC, Lee YJ, Yang YS, Ryu SB, Rim JS: Vitamin D receptor gene Alw I, Fok I, Apa I, and Taq I polymorphisms in patients with urinary stone. Urology 2010;75:923-927.

12 Gunes S, Bilen CY, Kara N, Asci R, Bagci H, Yilmaz AF: Vitamin D receptor gene polymorphisms in patients with urolithiasis. Urol Res 2006;34:47-52. 
13 Attia J, Thakkinstian A, D’Este C: Metaanalyses of molecular association studies: methodologic lessons for genetic epidemiology. J Clin Epidemiol 2003;56:297-303.

14 Thakkinstian A, McElduff P, D’Este C, Duffy D, Attia J: A method for meta-analysis of molecular association studies. Stat Med 2005;24:1291-1306.

15 Lau J, Ioannidis JP, Schmid CH: Quantitative synthesis in systematic reviews. Ann Intern Med 1997; 127:820-826.

-16 Zintzaras E, Ioannidis JP: Heterogeneity testing in meta-analysis of genome searches. Genet Epidemiol 2005;28:123-137.

17 Mantel N, Haenszel W: Statistical aspects of the analysis of data from retrospective studies of disease. J Natl Cancer Inst 1959;22: 719-748.

-18 DerSimonian R, Laird N: Meta-analysis in clinical trials. Control Clin Trials 1986;7: 177-188.

-19 Egger M, Davey Smith G, Schneider M, Minder C: Bias in meta-analysis detected by a simple, graphical test. BMJ 1997;315:629634.

20 Ruggiero M, Pacini S, Amato M, Aterini S, Chiarugi V: Association between vitamin D receptor gene polymorphism and nephrolithiasis. Miner Electrolyte Metab 1999;25: 185-190.

-21 Chen WC, Chen HY, Lu HF, Hsu CD, Tsai FJ: Association of the vitamin $\mathrm{D}$ receptor gene start codon Fok I polymorphism with calcium oxalate stone disease. BJU Int 2001;87: 168-171.

22 Heilberg IP, Teixeira SH, Martini LA, Boim MA: Vitamin D receptor gene polymorphism and bone mineral density in hypercalciuric calcium-stone-forming patients. Nephron 2002;90:51-57.

-23 Nishijima S, Sugaya K, Naito A, Morozumi M, Hatano T, Ogawa Y: Association of vitamin $\mathrm{D}$ receptor gene polymorphism with urolithiasis. J Urol 2002;167:2188-2191. 24 Vezzoli G, Soldati L, Proverbio MC, Adamo
D, Rubinacci A, Bianchi G, Mora S: Polymorphism of vitamin D receptor gene start codon in patients with calcium kidney stones. J Nephrol 2002;15:158-164.

-25 Ozkaya O, Soylemezoglu O, Misirlioglu M, Gonen S, Buyan N, Hasanoglu E: Polymorphisms in the vitamin $\mathrm{D}$ receptor gene and the risk of calcium nephrolithiasis in children. Eur Urol 2003;44:150-154.

-26 Relan V, Khullar M, Singh SK, Sharma SK: Association of vitamin D receptor genotypes with calcium excretion in nephrolithiatic subjects in northern India. Urol Res 2004;32: $236-240$.
27 Rendina D, Mossetti G, Viceconti R, Sorrentino M, Castaldo R, Manno G, Guadagno V, Strazzullo P, Nunziata V: Association between vitamin $D$ receptor gene polymorphisms and fasting idiopathic hypercalciuria in recurrent stone-forming patients. Urology 2004;64:833-838.

28 Bid HK, Chaudhary H, Mittal RD: Association of vitamin-D and calcitonin receptor gene polymorphism in paediatric nephrolithiasis. Pediatr Nephrol 2005;20:773-776.

29 Liu CC, Huang CH, Wu WJ, Huang SP, Chou YH, Li CC, Chai CY, Wu MT: Association of vitamin D receptor (Fok-I) polymorphism with the clinical presentation of calcium urolithiasis. BJU Int 2007;99:1534-1538.

30 Moyano MJ, Gomez de Tejada MJ, Garcia Lozano R, Moruno R, Ortega R, Marti V, Sanchez Palencia R, Miranda MJ, Palma A, Perez Cano R: Alterations in bone mineral metabolism in patients with calcium kidney stone disease and polymorphism of vitamin D receptor. Preliminary results (in Spanish) Nefrologia 2007;27:694-703.

-31 Seyhan S, Yavascaoglu I, Kilicarslan H, Dogan HS, Kordan Y: Association of vitamin D receptor gene Taq I polymorphism with recurrent urolithiasis in children. Int J Urol 2007; 14:1060-1062.

32 Mossetti G, Rendina D, Viceconti R, Manno G, Guadagno V, Strazzullo P, Nunziata V: The relationship of $3^{\prime}$ vitamin D receptor haplotypes to urinary supersaturation of calcium oxalate salts and to age at onset and familial prevalence of nephrolithiasis. Nephrol Dial Transplant 2004; 19:2259-2265.

33 Bid HK, Kumar A, Kapoor R, Mittal RD: Association of vitamin D receptor-gene (FokI) polymorphism with calcium oxalate nephrolithiasis. J Endourol 2005;19:111-115.

34 Wang S, Liu J, Hu S, Ye Z: Association of vitamin $D$ receptor gene polymorphisms with calcium oxalate calculus disease. J Huazhong Univ Sci Technol 2003;23:38-41.

35 Ferreira LG, Pereira AC, Heilberg IP: Vitamin D receptor and calcium-sensing receptor gene polymorphisms in hypercalciuric stone-forming patients. Nephron Clin Pract 2010;114:c135-c144.

36 Siddiqui AA, Mushtaq S: Urolithiasis: in search of new factors. J Pak Med Assoc 2008; 58:475-476.

37 Arcidiacono T, Terranegra A, Biasion R, Soldati L, Vezzoli G: Calcium kidney stones. Diagnostic and preventive prospects. G Ital Nefrol 2007;24:535-546.

38 Mittal RD, Bid HK, Manchanda PK, Kapoor $\mathrm{R}$ : Association of interleukin- $1 \beta$ gene and receptor antagonist polymorphisms with calcium oxalate urolithiasis. J Endourol 2007; 21:1565-1570.
39 Lai KC, Lin WY, Man KM, Tsai CH, Chen HY, Tsai FJ, Chen FJ, Chen HY, Liu HP, Ho TJ, Huang PH, Liu PL, Lin FY, Shen JL, Liu JT, Chen YH, Chen WC: Association of interleukin-18 gene polymorphisms with calcium oxalate kidney stone disease. Scand J Urol Nephrol 2010;44:20-26.

-40 Onaran M, Yilmaz A, Sen I, Ergun MA, Camtosun A, Kupeli B, Menevse S, Bozkirli I: A HindIII polymorphism of fibronectin gene is associated with nephrolithiasis. Urology 2009;74:1004-1007.

41 Ozturk M, Kordan Y, Cangul H, Dogan HS, Kilicarslan H, Vuruskan H, Oktay B: Association of urokinase gene $3^{\prime}$-UTR T/C polymorphism with calcium oxalate urolithiasis in children. Int Urol Nephrol 2008;40:563568.

42 Tsai FJ, Lin CC, Lu HF, Chen HY, Chen WC: Urokinase gene $3^{\prime}$-UTR T/C polymorphism is associated with urolithiasis. Urology 2002; 59:458-461.

43 Mittal RD, Bid HK, Kumar A, Bhandari M: Association of urokinase gene $3^{\prime}$-UTR polymorphism with calcium oxalate nephrolithiasis. J Endourol 2006;20:157-160.

44 Haussler MR, Whitfield GK, Haussler CA, Hsieh JC, Thompson PD, Selznick SH, Dominguez CE, Jurutka PW: The nuclear vitamin D receptor: biological and molecular regulatory properties revealed. J Bone Miner Res 1998;13:325-349.

45 Li XQ, Tembe V, Horwitz GM, Bushinsky DA, Favus MJ: Increased intestinal vitamin $\mathrm{D}$ receptor in genetic hypercalciuric rats. A cause of intestinal calcium hyperabsorption. J Clin Invest 1993;91:661-667.

-46 Zhu C, Ye Z, Chen Z, Xia D, Hu J: Association between vitamin $\mathrm{D}$ receptor gene polymorphisms and idiopathic hypocitraturia in the Chinese population. Urol Int 2010;85:100105.

47 Zerwekh JE, Hughes MR, Reed BY, Breslau NA, Heller HJ, Lemke M, Nasonkin I, Pak CY: Evidence for normal vitamin D receptor messenger ribonucleic acid and genotype in absorptive hypercalciuria. J Clin Endocrinol Metab 1995;80:2960-2965.

48 Jurutka PW, Remus LS, Whitfield GK, Thompson PD, Hsieh JC, Zitzer H, Tavakkoli P, Galligan MA, Dang HT, Haussler CA, Haussler MR: The polymorphic N-terminus in human vitamin D receptor isoforms influences transcriptional activity by modulating interaction with transcription factor IIB. Mol Endocrinol 2000;14:401-420.

-49 Ingles SA, Haile RW, Henderson BE, Kolonel LN, Nakaichi G, Shi CY, Yu MC, Ross RK, Coetzee GA: Strength of linkage disequilibrium between two vitamin $\mathrm{D}$ receptor markers in five ethnic groups: implications for association studies. Cancer Epidemiol Biomarkers Prev 1997;6:93-98. 